\title{
Variation for Epicuticular Waxes on Onion Foliage and Impacts on Numbers of Onion Thrips
}

\author{
Steven J. Damon \\ Department of Horticulture, 1575 Linden Drive, University of Wisconsin, Madison, WI 53706 \\ Russell L. Groves \\ Department of Entomology, 1630 Linden Drive, University of Wisconsin, Madison, WI 53706 \\ Michael J. Havey ${ }^{1}$ \\ Vegetable Crops Unit, Agricultural Research Service, U.S. Department of Agriculture, Department of \\ Horticulture, 1575 Linden Drive, University of Wisconsin, Madison, WI 53706
}

\begin{abstract}
Additional INDEX words. Allium cepa, GC/MS, SEM, Thrips tabaci
Abstract. Natural variation exists in onion (Allium cepa L.) for amounts of epicuticular waxes on foliage, and plants with lower amounts of these waxes suffer less feeding damage from onion thrips (Thrips tabaci Lind.). Wild-type onion possesses copious amounts of epicuticular waxes and is often referred to as "waxy." The recessively inherited "glossy" phenotype has significantly less wax relative to waxy types and shows resistance to onion thrips but is vulnerable to spray damage, foliar pathogens, and excessive transpiration. Phenotypes visually intermediate between waxy and glossy also exist in onion, which we refer to as "semiglossy." Epicuticular waxes on the leaves of glossy, semiglossy, and waxy onions were evaluated for appearance using scanning electron microscopy (SEM) and amounts and types were analyzed using gas chromatography/mass spectrometry. Wax crystals were clearly visible on the surface of waxy foliage with decreasing amounts on semiglossy and none on glossy leaves. The ketone hentriacontanone16 was the most prevalent wax on leaves of waxy onion and was significantly $(P<0.01)$ less on semiglossy relative to waxy plants and on glossy relative to waxy and semiglossy plants. Numbers of adult and immature onion thrips were significantly reduced $(P<0.05)$ on glossy and/or semiglossy accessions relative to waxy in field and greenhouse cage experiments. These results indicate that semiglossy plants possess intermediate amounts of epicuticular waxes that may protect leaves from diseases or environmental stresses while still conferring resistance to onion thrips. Therefore, the semiglossy phenotype should be useful in integrated programs managing this important onion pest.
\end{abstract}

Onion thrips is an important insect pest of onion causing direct damage to leaves and stored bulbs (Alston and Drost, 2008), reduced bulb and seed yields (Elmore, 1949; Jones et al., 1934), and transmission of serious pathogens such as iris yellow spot virus (Gent et al., 2004; Shock et al., 2008). Effective control of onion thrips necessitates frequent insecticide applications (Alston and Drost, 2008) with the unfortunate result of increased resistance to commonly used chemicals (Allen et al., 2005; Herron et al., 2008; Shelton et al., 2006). Genetic resistance to thrips may help to reduce pesticide applications and offer a potentially sustainable management strategy for this important pest. Epidermal thickness contributed to differences in onion thrips populations across 16 cultivars of cotton [Gossypium hirsutum L. (Abdel-Gawaad et al., 1973)]. Conversely epidermal thickness did not contribute to differences for numbers of onion thrips across six cultivars of white cabbage [Brassica oleracea L. var. capitata L. (Balint et al., 2013)].

Received for publication 9 Apr. 2014. Accepted for publication 20 May 2014. We gratefully acknowledge the support of grant number 2008-51180-04875 from the USDA Specialty Crops Research Initiative and a Monsanto Graduate Fellowship to S.J. Damon. We thank Dr. George Kennedy, North Carolina State University, for onion thrips and Dean Kincaid family farms, Palmyra Wisconsin, for field space. Electron microscopy was performed at the Newcomb Imaging Center, Department of Botany, University of Wisconsin-Madison. Names are necessary to report factually on available data; however, the U.S. Department of Agriculture (USDA) neither guarantees nor warrants the standard of the product, and the use of the name by USDA implies no approval of the product to the exclusion of others that may also be suitable.

${ }^{1}$ Corresponding author. E-mail: mjhavey@wisc.edu.
Resistances to onion and/or western flower thrips (Frankliniella schultzei Trybom) have been reported in cowpea [Vigna unguiculata (L.) Walp (Muchero et al., 2010)] and sunflower [Helianthus annuus L. (Ashfaq and Aslam, 2001)]; however, specific mechanisms were not determined.

Leaf epicuticular waxes are important in plant-insect interactions and are associated with both attractive and repulsive responses (Eigenbrode and Espelie, 1995; Woodhead and Chapman, 1986). Epicuticular waxes accumulate on leaves of essentially all terrestrial plants and provide protection against water loss, pathogens, and chemicals (Baker, 1982). Several classes of lipids have been identified in plant epicuticular waxes, including alkanes and ketones of odd chain length and esters, fatty alcohols, and fatty acids of even chain length (Eigenbrode and Espelie, 1995; Tulloch, 1976). Sorghum [Sorghum bicolor (L.) Moench] cultivars with less wax showed resistance to greenbug [Schizaphis graminum Rondani (Starks and Weibel, 1981)], whereas alfalfa (Medicago sativa L.) with more wax was resistant to spotted alfalfa aphid [Therioaphis maculata Buckton (Bergman et al., 1991)]. Insects may also show tactile responses to epicuticular waxes (Eigenbrode, 2004). For example, the chrysomelid beetle (Phaedon cochleariae F.) was observed sliding off of waxy leaves of $B$. oleracea while showing increased traction on less waxy leaves held at the same angle (Stork, 1980). Another hypothesis is that insects respond to specific waxes as they actively evaluate the plant for feeding or ovipositioning (Blaney and Chapman, 1970; Städler, 1986; Thibout et al., 1982).

Wild-type onion foliage accumulates large amounts of epicuticular waxes resulting in a blue-gray color, which often 
is referred to as "waxy." Jones et al. (1934) observed that the onion cultivar White Persian had a lighter green foliage color, which reduced onion thrips populations and the amount of feeding damage as compared with blue-gray foliage. Jones et al. (1944) subsequently referred to the foliage type from "White Persian' as "glossy" and demonstrated that it is conditioned by the recessive $g l$ locus. Subsequent reports have documented that glossy onions show resistance to onion thrips (Alimousavi et al., 2007; Molenaar, 1984; Mote and Sonone, 1977; Pawar et al., 1975). Molenaar (1984) observed that glossy onions have less epicuticular wax than waxy leaves. Although imparting greater resistance to onion thrips, glossy foliage is not commercially viable because plants show susceptibility to leaf pathogens, excessive transpiration, and spray injury (Baker, 1982; Mohan and Molenaar 2005; Molenaar, 1984). There exists natural variation in onion for amounts of epicuticular waxes intermediate between glossy and waxy types. Jones et al. (1935) described 'Sweet Spanish' populations as having an intermediate "shade" of foliage relative to glossy and waxy onions, which we refer to as "semiglossy." These semiglossy types are lighter green in color, are associated with reduced onion thrips populations, and suffer less damage relative to waxy onions (Diaz-Montano et al., 2010; Maughan and MacLeod, 1936). Because semiglossy onions have intermediate amounts of wax, this phenotype may be useful in an integrated approach to manage onion thrips by reducing sprays and the incidence of thrips-transmitted diseases while maintaining the protection of some wax accumulation on leaves. In this study, we evaluated amounts and types of epicuticular waxes on the leaves of glossy, semiglossy, and waxy onions as well as assessed numbers of adult and larval onion thrips in replicated field and greenhouse cage experiments.

\section{Materials and Methods}

Plant materials. Doubled-haploid (DH) onions 2107 and 2150 (Alan et al., 2004) have waxy foliage. U.S. Department of Agriculture (USDA) PI 546303 is a glossy inbred line (B9885C) derived from 'White Persian' (Molenaar, 1984). USDA inbred B5351C (cage 905-3) selected from 'Colorado \#6' and an $\mathrm{S}_{1}$ family from PI 264320 (USDA breeding plot 22142) of 'Sweet Spanish' background (SG-A and SG-B, respectively) are semiglossy types with light green foliage and less visible wax as compared with waxy onions.

SCANNING ELECTRON MICROSCOPY OF EPICUTICULAR WAX MORPHOLOGY. Seeds of accessions DH2107, B9885C, 22142, and B5351C were planted in Jan. 2012 in a greenhouse on the University of Wisconsin-Madison (UW) campus. Initial daylength was set at $12 \mathrm{~h}$ and was increased on the first of each subsequent month after the spring equinox to the natural daylength in Madison, WI. Temperatures were $25{ }^{\circ} \mathrm{C}$ days and $20^{\circ} \mathrm{C}$ nights. In Apr. 2012, leaf samples were collected from each accession for analysis (Laudate, 2003) on an FEI Quanta scanning electron microscope. Because the electron beam began to melt waxes within $30 \mathrm{~s}$, various settings were evaluated and the best were $30 \mathrm{kV}$, pressure $=3$ torr, spot size $=$ 5 , brightness $=47$, and contrast $=97$. Micrographs were visually inspected for relative amounts and morphologies of wax crystals on the leaf surface of the waxy, semiglossy, and glossy phenotypes.

GAS CHROMATOGRAPHY/MASS SPECTROMETRY ANALYSES OF EPICUTICULAR WAXES. In Feb. 2012, five plants of each of the four accessions were transplanted into $20-\mathrm{cm}$ pots for a total of 20 plants. In Apr. 2012, three samples were collected from a single leaf from each of the 20 plants for a total of 60 samples. In May 2012, two samples were collected from an older leaf and two from a younger leaf from each of the 20 plants for a total of 80 samples. In June 2012, the same procedure was followed as for the May sampling to yield another 80 samples.

In May 2013, seeds of the four accessions were planted in $10-\mathrm{cm}$ pots at the UW greenhouses and in four randomly assigned field plots at the Dean Kincaid farm near Palmyra, WI. In June 2013, five greenhouse-grown plants of each accession were transplanted into $20-\mathrm{cm}$ pots for a total of 20 plants. Greenhouse-grown plants of the four accessions were also transplanted in 2013 into four randomly assigned field plots at the UW Horticulture Research Station near Arlington, WI. At each of the three environments, leaf samples from the four accessions were collected once per month for 3 months for analysis of epicuticular waxes by gas chromatography/mass spectrometry (GC/MS). In June 2013 at the UW greenhouses, two samples were collected from different leaves from each of the 20 plants for a total of 40 samples. In July and Aug. 2013, the same procedure was followed as for the June sampling to yield another 40 samples each month. In June 2013 at each of the Arlington and Palmyra field locations, five randomly selected plants were chosen from each of four plots containing the four accessions for a total of 20 plants. Two samples were collected from different leaves from each of the 20 plants for a total of 40 samples. In July and Aug. 2013, the same procedure was followed as for the June sampling to yield another 40 samples each month from each field location. In total, 12 samplings occurred across four (two greenhouse and two field) environments and yielded a total of 580 samples.

Immediately after sampling, the fresh weight in grams of each leaf piece was measured and an aliquot of docosane (Sigma-Aldrich, St. Louis, MO), dissolved in high-performance liquid chromatography (HPLC) reagent grade chloroform (Fisher Scientific, Hampton, NH), was applied to the leaf sample at the rate of $1 \mu \mathrm{g}$ per $0.3 \mathrm{~g}$ of tissue and allowed to airdry. Leaf pieces were placed in $16 \times 100-\mathrm{mm}$ glass vials (Fisher Scientific) and covered with aluminum foil for immediate transport to the laboratory. Epicuticular waxes were extracted by adding enough HPLC reagent-grade chloroform to each vial to submerge the leaf sample for $60 \mathrm{~s}$. Leaf tissue was removed and discarded. Chloroform in vials was allowed to evaporate in a fume hood without agitation. After evaporation, $500 \mu \mathrm{L}$ of anhydrous grade chloroform, $600 \mu \mathrm{L}$ of acetonitrile, and $210 \mu \mathrm{L}$ of the derivatization agent $\mathrm{N}, \mathrm{O}$-Bis(trimethylsilyl)trifluoroacetamide (BSTFA) were added to each vial (all from Sigma-Aldrich). Vials were capped with phenolic polytetrafluoroethylene (PTFE)-lined caps (Kimble Chase, Rockwood, TN) and derivatized in an oven at $80^{\circ} \mathrm{C}$ for $30 \mathrm{~min}$. Each sample was filtered through a Supelco Iso-disc PTFE-13-2 filter (Sigma-Aldrich) into a Supelco 2-mL PTFE/Silcone (Sigma-Aldrich) capped glass vial using a 1-mL disposable syringe (Fisher Scientific). The samples were analyzed on a GC/MS (GCMS-QP2010 SE; Shimadzu, Kyoto, Japan) equipped with an SHRXI-5MS column and an AOC-5000 autoinjector. The machine used a split/splitless glass inlet liner, Thermolite septum (Restek, Bellefonte, PA), and a $10-\mu \mathrm{L}$ Hamilton syringe. Each sample cycle began with split injection (ratio $=1 / 20$ ) of $1 \mu \mathrm{L}$ of sample at $250{ }^{\circ} \mathrm{C}$ and used a programmed column temperature consisting of $10 \mathrm{~min}$ at $150^{\circ} \mathrm{C}, 15 \mathrm{~min}$ increasing temperature 
at a rate of $10{ }^{\circ} \mathrm{C} \cdot \mathrm{min}^{-1}$, and $10 \mathrm{~min}$ at $300{ }^{\circ} \mathrm{C}$. Mass scan range was between 35 and $600 \mathrm{~m} / \mathrm{z}$. Chemical compounds in each sample were identified by post-run software (Shimadzu) comparing mass spectra with a library (NIST11) with a similarity threshold of $80 \%$. Quantities were estimated by the area under peaks on the total ion chromatogram. All peak areas were normalized to the docosane internal standard. Relative retention times were calculated by dividing compound retention times by those of the internal standard docosane.

Statistical Analyses of GCMS Results. A mixed-model analysis of variance (ANOVA) using the repeated-measures option was performed in SAS (Version 9.3; SAS Institute, Cary, NC). Individual plants were regarded as experimental units and the three sampling time points were considered as repeated measures. GC/MS data for each compound was considered as a unique, dependent variable. Accessions and samplings were considered as fixed and environments, plants, and subsamples as random variables. Departure from normality of model residuals was corrected by a square-root transformation. Significant differences for quantities of compounds detected by GC/MS were determined using least-squared means and probability values of all pairwise comparisons among accessions.

Confirmation of COMPounds detected by GCMS. After determining the most prevalent compounds associated with the foliar phenotypes, hentriacontanone-16, triacontanol-1, and octacosanol-1 were obtained from TCI Chemicals (Portland, OR). These compounds and docosane were prepared for GC/MS analysis according to the method of standard addition (Harris, 2003) to confirm the identities of these epicuticular waxes and to calculate absolute quantities. Four leaf samples from waxy DH2150 were separately submerged into $2 \mathrm{~mL}$ of HPLC reagentgrade chloroform as previously described. Three dilutions of the four compounds were made in HPLC reagent-grade chloroform at 1,5 , and $10 \mu \mathrm{g} \cdot \mathrm{mL}^{-1}$ in a final volume of $500 \mu \mathrm{L}$. A fourth vial was filled with $500 \mu \mathrm{L}$ of chloroform for each set of dilutions. Five hundred microliters of the epicuticular wax solution from DH2150 were added to each of the four vials for each compound; then $500 \mu \mathrm{L}$ of acetonitrile and $200 \mu \mathrm{L}$ of BSTFA were added to each vial. Vials were capped, derivatized, filtered, and analyzed on the GC/MS as previously described. The retention times and mass spectra of peaks for the three compounds from TCI Chemicals were compared with the epicuticular waxes from DH2150. A linear regression of peak areas against concentrations for each set of dilutions was performed. The difference between the origin and $\mathrm{X}$-intercept provided the concentration of the compound from the DH2150 leaf sample. The regression slopes for octacosanol-1, triacontanol-1, and hentriacontanone-16 were then used to calculate concentrations represented by peak area least square means for each of the waxes. Concentrations of other fatty alcohols were calculated using the average slope of octacosanol-1 and triacontanol-1. Other alkane compound concentrations were calculated using the docosane regression. Based on sample fresh tissue weights and compound concentrations, micrograms of wax per gram of fresh leaf tissue were calculated for each compound for each of the four accessions.

ASSESSMENT OF ONION THRIPS POPULATIONS ON FOLIAGE TYPES. In May 2013, the four accessions were planted in fields at the UW Horticulture Research Farm near Arlington, WI, and at Dean Kincaid farm near Palmyra, WI. Each field had four replications of the four accessions in a $4 \times 4$ Latin-square design with 30 to 50 plants in each 4-m plot. A Latin-square design was selected to increase the likelihood that replicate sets of experimental treatments (accessions) would be equally exposed to mobile, colonizing adult onion thrips that could disperse into experiment plots from several directions. Plots at Arlington were not sprayed with insecticide; Palmyra plots received five insecticide sprays between 7 Aug. and 3 Sept. based on established thresholds for onion thrips management (Nault et al., 2012). Plots were sampled by cutting two randomly selected plants at the soil level and placing them in 3.8-L plastic zip-lock bags. The bags were transported to Madison where 500 $\mathrm{mL}$ of $95 \%$ ethanol was added. Each bag was agitated for $3 \mathrm{~min}$ to wash all life stages (except eggs) off of the plant. Plants were discarded and insects were recovered by filtering the ethanol through 150- $\mu \mathrm{m}$ screens (Greenhouse Megastore, Danville, IL). All adult and larval stages of onion thrips were counted under a stereoscope. Onion thrips were first observed on accessions at Arlington in mid-July and sampling occurred on a weekly basis for 4 weeks thereafter. Onion thrips were first observed at Palmyra at the end of August and population sampling occurred twice over the next 2 weeks.

For choice and no-choice cage experiments in the greenhouse, onion thrips were obtained from G.G. Kennedy (North Carolina State University, Raleigh, NC) and maintained on the laboratory bench at ambient conditions using a $13 \times 20-\mathrm{cm}$ plastic container with fresh cabbage leaves replaced every 3 to $4 \mathrm{~d}$. For the choice experiments, 10 cylindrical cages were constructed from $30 \times 76-\mathrm{cm}$ polyethylene plastic sheets (Interstate Plastics, Sacramento, CA) bonded on the $30-\mathrm{cm}$ edges with tape (Killer Red Tape; ePlastics, San Diego, CA). One end of each cylinder was covered with thrips proof $150-\mu \mathrm{m}$ screen using plastic adhesive glue (Weld-on 16; ePlastics). The open end of each cage fit inside the rim of a $25-\mathrm{cm}$ pot. One plant of each accession was planted in each of $1025-\mathrm{cm}$ pots and cages were placed over each pot. Fifty adult onion thrips were collected from the colony by aspiration into a glass pipet and introduced into each cage by placing the pipet upright in the center of the pot and left undisturbed for $14 \mathrm{~d}$. For the no-choice experiments, 20 cylindrical cages were built from $30 \times 61-\mathrm{cm}$ polyethylene plastic sheets bonded on the $30-\mathrm{cm}$ edges with killer red tape and covered with thrips-proof $150-\mu \mathrm{m}$ screen as described previously. The open end of each cage fit within the rim of a $20-\mathrm{cm}$ pot. Five plants of each accession were planted separately in $2020-\mathrm{cm}$ pots and cages placed over each pot. Each cage was infested with 30 adult onion thrips as described previously. Plants from choice and no-choice experiments were harvested into gallon plastic zip-lock bags and weighed. Plants were washed with ethanol and insects counted as previously described.

EXPERIMENTAL DESIGN AND STATISTICAL ANALYSIS OF NUMBERS OF ONION THRIPS. For 2013 field experiments at Arlington and Palmyra, a mixed-model ANOVA with the repeated-measures option was performed in SAS (SAS Institute, Inc., Cary, NC) to assess the effect of onion accession on numbers of adult and larval onion thrips. Plots were considered as experimental units and the four sampling at Arlington and two at Palmyra were considered as repeated measures. Adult and larval numbers per plant were dependent variables. Accessions were considered fixed and environments, range, row, and subsamples as random. For the experiments at UW greenhouses, a mixed-model ANOVA was performed and cages were considered as replications and individual plants as experimental units. Adult and larval counts were considered as dependent variables. 
Accessions were considered fixed and replication as random. Plant weight was used as a covariate to account for a possible attraction of onion thrips to larger plants.

\section{Results and Discussion}

EPICUTICULAR WAX MORPHOLOGY. SEM micrographs (Fig. 1) revealed no obvious wax crystals on glossy leaves, a thin scattering of spiky, plate-like crystals on semiglossy leaves, and large quantities of the spiky, plate-like crystals on waxy leaves. According to descriptions of epicuticular wax crystals by Jeffree (1986), the spiky crystals on onion foliage are likely formed by a ketone. Studies by Gülz et al. $(1992,1993)$ concluded that characteristic lipid crystals can be observed on leaves if one lipid class comprises at least $40 \%$ of the total profile and if at least $80 \%$ of that class is one compound. Therefore, SEM indicated that ketone(s) may predominate in the epicuticular waxes on onion foliage.

GCMS ANALYSIS OF EPICUTICULAR WAX. GC/MS is a powerful technique for identifying and quantifying epicuticular waxes (Kolattukudy and Espelie, 1985; Tulloch, 1976; Walton, 1990) and revealed carbohydrate, short hydrocarbon, and long hydrocarbon chain (wax) compounds in chloroform-extracted samples from onion leaves. Pairwise comparisons among wax compounds accounted for the vast majority of the highly significant $(P<0.01)$ differences among glossy, semiglossy, and waxy phenotypes. Twenty-one comparisons among eight wax compounds (Table 1) and two comparisons among two non-wax compounds (butanedioic acid and myo-inositol) were significantly different at $P<0.01$. The two non-wax compounds likely originated from injured leaf cells and may not contribute significantly to compounds on leaf surfaces. Accession-bysampling interactions were not significant for wax compounds, revealing that differences for amounts of waxes were similar over time in both field and greenhouse environments.

Hentriacontanone-16 as the most prevalent on waxy leaves (Table 1) and its quantities were significantly different among waxy, semiglossy, and glossy accessions (Table 2). Relative to waxy, quantities of this ketone were intermediate on semiglossy and lowest on glossy leaves. These GC/MS results are consistent with the morphology of wax crystals under SEM. Hentriacontanone-16 forms crystals at concentrations as low as $23 \%$ of total waxes (Gülz et al., 1992); crystals were observed on waxy (52\%) and semiglossy (35\% to $39 \%)$ but not glossy (19\%), leaves (Table 1). The crystals observed on waxy leaves were also similar in appearance to those of hentriacontanone-16 on the "cross-rippled" leaf surface of Liriodendron tulipifera L. (Gülz et al., 1992). SEM and GC/MS analyses provide strong evidence that hentriacontanone-16 is the predominant epicuticular wax on onion foliage and the most reduced in the glossy and semiglossy phenotypes. Rhee et al. (1998) reported that hentriacontanone16 is the predominant epicuticular wax on leek (Allium ampeloprasum $\mathrm{L}$.) foliage.

Other waxes detected by GC/MS included four fatty alcohols (hexacosanol-1, octacosanol-1, heptadecanol-1, and triacontanol-1) and three alkanes (heptacosane, 1-ethenyloxy octadecane, and 2-methyl octacosane). Similar amounts of octacosanol-1 and triacontanol-1 on waxy and glossy leaves suggest that these compounds do not contribute to the visual phenotype. Quantities of other waxes were relatively small, albeit significantly $(P<0.01)$ different in several pairwise comparisons among accessions. Four of the eight waxes in Table 1 were significantly $(P<0.01)$ different between the two semiglossy accessions (B5351C and 22142), revealing that phenotypically similar plants have different amounts of specific waxes. The total amount of wax on the leaves of semiglossy B5351C was not significantly different from glossy B9885C (Table 2); however, B5351C accumulated enough hentriacontanone-16 (39\% of total waxes) to appear visually as semiglossy (Table 1).

Comparison of mass spectra and retention times between commercially available hentriacontanone-16, octacosanol-1, and triacontanol-1 and samples of epicuticular waxes from leaves of waxy DH2150 confirmed the identities of these compounds. Standard addition regression lines were used to estimate quantities in micrograms of waxes per gram of leaf tissue across the four accessions (Table 2).

Numbers OF ONION THRIPS. Numbers of adult and larval onion thrips in the field choice experiments were significantly $(P<0.05)$ different between waxy DH2107 and the other accessions, but there were no significant differences among the glossy and semiglossy onions (Table 3 ). Larval numbers were higher than adults (Table 3 ) and presumably are responsible for most of the direct damage to leaf tissues (Coudriet et al., 1979). As expected, infestation levels at Palmyra were much lower than Arlington as a result of insecticide sprays. Numbers of adults were not significantly different among accessions at Palmyra; however, differences for larvae between DH2107 and
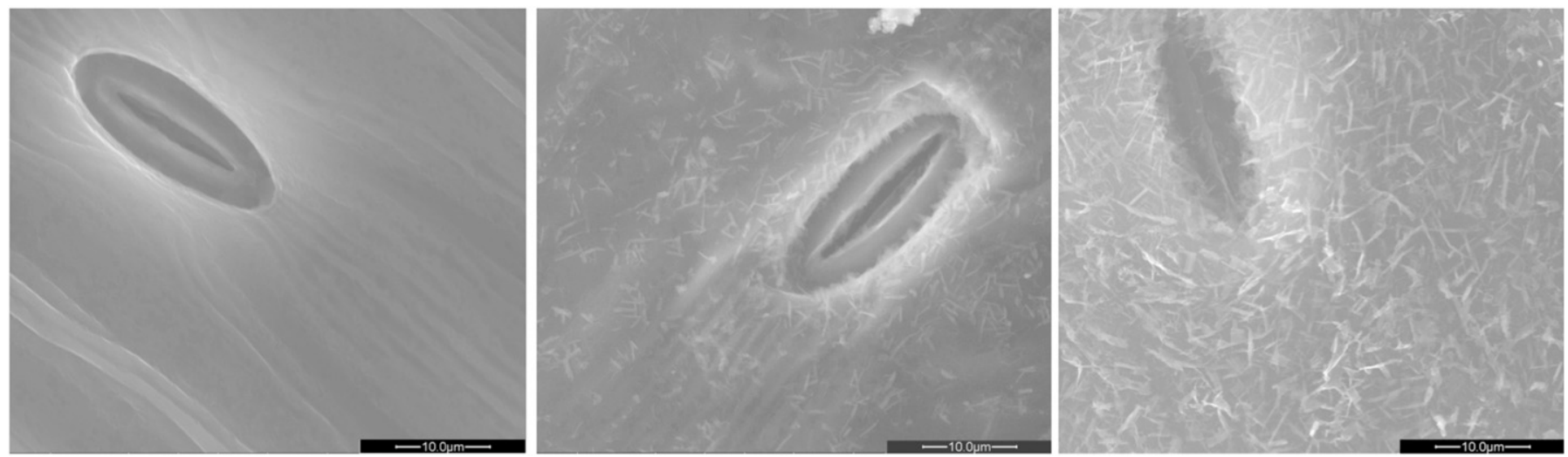

Fig. 1. Scanning electron micrographs of surfaces of glossy B9885C (left), semiglossy 22142 (middle), and waxy DH2107 (right) onion leaves at magnification of $5000 \times$. Elliptical shapes are stomata and $10-\mu \mathrm{m}$ scales are shown in lower right corners. 
both $\mathrm{B} 9885 \mathrm{C}$ and $\mathrm{B} 5351 \mathrm{C}$ were significant $(P<0.05)$. Overall, the field results indicate that semiglossy plants may support fewer adults and larvae of onion thrips relative to waxy while retaining more epicuticular waxes than the glossy phenotype.

In the caged choice experiments, larval numbers were significantly $(P<0.05)$ different between waxy DH2107 and the two semiglossy accessions, but not between glossy B9885C and waxy DH2107 (Table 3). Numbers of adult onion thrips in

Table 1. Major epicuticular waxes, formulas, relative retention time (RRT), and percent of total waxes detected using gas chromatography/mass spectrometry on leaves of four onion accessions evaluated across four environments.

\begin{tabular}{lllrrrr}
\hline & & & \multicolumn{3}{c}{ Waxes (\% of total) $)^{\mathrm{z}}$} \\
\cline { 4 - 7 } Compound & Formula & RRT & GL & SG-A & SG-B & WX \\
\hline Hentriacontanone-16 & $\mathrm{C}_{31} \mathrm{H}_{62} \mathrm{O}$ & 1.47 & 19.0 & 39.0 & 34.7 & 52.0 \\
Heptacosane & $\mathrm{C}_{27} \mathrm{H}_{56}$ & 1.37 & 1.4 & 9.5 & 2.5 & 1.4 \\
Heptadecanol-1 & $\mathrm{C}_{17} \mathrm{H}_{36} \mathrm{O}$ & 1.45 & 3.3 & 8.5 & 4.1 & 6.2 \\
Hexacosanol-1 & $\mathrm{C}_{26} \mathrm{H}_{54} \mathrm{O}$ & 1.31 & 6.3 & 3.0 & 4.6 & 2.5 \\
Octacosanol-1 & $\mathrm{C}_{28} \mathrm{H}_{58} \mathrm{O}$ & 1.39 & 52.0 & 24.3 & 35.3 & 26.4 \\
1-Ethenyloxy octadecane & $\mathrm{C}_{20} \mathrm{H}_{40} \mathrm{O}$ & 1.35 & 3.4 & 2.3 & 1.1 & 1.1 \\
2-Methyl octacosane & $\mathrm{C}_{29} \mathrm{H}_{60}$ & 1.29 & 1.6 & 4.1 & 1.8 & 0.8 \\
Triacontanol-1 & $\mathrm{C}_{30} \mathrm{H}_{62} \mathrm{O}$ & 1.50 & 13.0 & 9.4 & 16.1 & 9.6 \\
\hline
\end{tabular}

${ }^{\mathrm{z}} \mathrm{GL}=$ glossy B9885C; SG-A = semiglossy B5351C; SG-B = semiglossy 22142; WX = waxy DH2107.

Table 2. Amounts in micrograms of eight epicuticular waxes per gram of fresh leaf tissue and least significant differences calculated from least squares means of gas chromatograph peak areas for four onion accessions across four environments.

\begin{tabular}{|c|c|c|c|c|c|c|}
\hline \multirow[b]{2}{*}{ Compound } & \multicolumn{4}{|c|}{ Amount of waxes $\left(\mu \mathrm{g} \cdot \mathrm{g}^{-1}\right)^{z}$} & \multicolumn{2}{|c|}{ Least significant difference } \\
\hline & GL & SG-A & SG-B & $\overline{\mathrm{WX}}$ & 0.05 & 0.01 \\
\hline Hentriacontanone-16 & 13.1 & 20.5 & 31.8 & 83.4 & 15.0 & 19.8 \\
\hline Heptacosane & 0.9 & 5.0 & 2.3 & 2.2 & 1.2 & 1.6 \\
\hline Heptadecanol-1 & 2.3 & 4.5 & 3.7 & 9.9 & 1.6 & 2.1 \\
\hline Hexacosanol-1 & 4.4 & 1.6 & 4.2 & 4.0 & 2.2 & 2.8 \\
\hline Octacosanol-1 & 35.9 & 12.8 & 32.4 & 42.4 & 13.9 & 18.3 \\
\hline 1-Ethenyloxy octadecane & 2.4 & 1.2 & 1.0 & 1.8 & 0.8 & 1.0 \\
\hline 2-Methyl octacosane & 1.1 & 2.1 & 1.7 & 1.2 & 0.6 & 0.8 \\
\hline Triacontanol-1 & 9.0 & 4.9 & 14.7 & 15.4 & 3.4 & 4.5 \\
\hline Total wax & 69.1 & 52.6 & 91.8 & 160.3 & 38.7 & 50.9 \\
\hline
\end{tabular}

${ }^{\mathrm{z}} \mathrm{GL}=$ glossy B9885C; SG-A = semiglossy B5351C; SG-B = semiglossy 22142; WX = waxy DH2107.

Table 3. Least squares means and least significant differences for numbers of adult and larval onion thrips per plant in field choice and greenhouse choice and no-choice experiments.

\begin{tabular}{lllrrrrr}
\hline \multirow{2}{*}{ Location $^{\mathrm{z}}$} & & & \multicolumn{3}{c}{ Mean accessions (no.) } & Least significant \\
\cline { 3 - 6 } Arlington & Cheatment & Stage & GL & SG-A & SG-B & WX & difference (0.05) \\
\cline { 3 - 6 } Palmyra & Adults & 3.1 & 2.7 & 2.7 & 7.2 & 2.6 \\
& \multirow{2}{*}{ Choice } & Larvae & 15.7 & 12.1 & 15.5 & 77.8 & 14.7 \\
& & Adults & 0.7 & 1.1 & 1.6 & 1.3 & 1.2 \\
& Larvae & 3.4 & 1.9 & 5.5 & 5.7 & 2.2 \\
& \multirow{2}{*}{ Choice } & Adults & 3.9 & 3.4 & 2.8 & 3.1 & 1.8 \\
& \multirow{2}{*}{ No-choice } & Larvae & 44.3 & 25.2 & 20.9 & 41.3 & 15.3 \\
& & Adults & 3.6 & 3.0 & 2.1 & 6.4 & 1.9 \\
& & Larvae & 45.8 & 55.1 & 36.3 & 69.2 & 27.3 \\
\hline
\end{tabular}

${ }^{\mathrm{z}}$ Arlington $=$ University of Wisconsin Horticulture Research Station near Arlington, WI; Palmyra $=$ Dean Kincaid farm near Palmyra, WI.

${ }^{\mathrm{y}} \mathrm{GL}=$ glossy B9885C; SG-A = semiglossy B5351C; SG-B = semiglossy 22142; WX = waxy DH2107. the no-choice experiment revealed significant differences waxy DH2107 and the other accessions and between (1985) observed resistance to grain aphid (Sitobion avenae F.) on glossy wheat (Triticum field but found that differences in both wax bloom and resistance were diminished in a greenhouse environment. Similarly, we observed fewer significant differences for numbers of onion thrips among accessions in our greenhouse experiments.

Fewer onion thrips in the field and cage experiments were consistent with reduced amounts of epicuticular waxes, suggesting that specific waxes or total wax amounts may be important for either host recognition by the insect or preference for feeding or ovipositioning. Although statistical analyses considered accessions as a fixed variable and greenhouse experiments had fewer significant differences among the onion accessions for numbers of onion thrips, our results agree with other reports that the glossy and semiglossy phenotypes of onion significantly contribute to onion thrips resistance (Alimousavi et al., 2007; Diaz-Montano et al., 2010; Jones et al., 1934; Maughan and MacLeod, 1936; Molenaar, 1984; Mote and Sonone, 1977; Pawar et al., 1975). Types of insect resistance in plants have been classified into three general categories: antixenosis (non-preference), antibiosis, and tolerance (Kogan and Ortman, 1978; Painter, 1951). Antibiosis refers to plant characteristics that have an adverse effect as the insect feeds. Tolerance refers to the ability of an infested plant to perform similarly to non-infested plants under comparable pest population densities. Antixenosis refers to the existence of plant characteristics that repel insects or do not induce an important host-recognition behavioral response. Lower amounts of total wax, or less of specific waxes such as hentriacontanone16 , on leaf surfaces could be less attractive to onion thrips (antixenosis) and/or have an adverse effect on the insect as it feeds or reproduces (antibiosis). Lower numbers of onion thrips on semiglossy foliage, 
together with protection from diseases or environmental stresses provided by intermediate amounts of epicuticular waxes, support the commercial use of this phenotype to potentially reduce the number of insecticide sprays over the production season.

\section{Literature Cited}

Abdel-Gawaad, A.A.W., F.H. El-Gayar, A.S. Soliman, and O.A. Zaghlool. 1973. Studies on Thrips tabaci Lindeman X. Mechanism of resistance to Thrips tabaci L. in cotton varieties. Zeitschrift fur angewandte Entomologie 73:251-255.

Alan, A.R., A. Brants, E. Cobb, P.A. Goldschmied, M.A. Mutschler, and E.D. Earle. 2004. Fecund gynogenic lines from onion (Allium cepa L.) breeding materials. Plant Sci. 167:1055-1066.

Alimousavi, S.A., M.R. Hassandokht, and S. Moharramipour. 2007. Evaluation of Iranian onion germplasms for resistance to thrips. Intl. J. Agr. Biol. 9:897-900.

Allen, J.K.M., C.D. Scott-Dupree, J.H. Tolman, and C.R. Harris. 2005. Resistance of Thrips tabaci to pyrethroid and organophosphate insecticides in Ontario, Canada. Pest Mgt. Sci. 61:809815.

Alston, D.G. and D. Drost. 2008. Utah pests fact sheet: Onion thrips. Utah State Univ. Ext., Utah Plant Pest Diagnostic Lab. ENT-11708PR.

Ashfaq, M. and M. Aslam. 2001. Resistance of different sunflower (Helianthus annuus Linnaeus, Compositae) genotypes against the attack of Aphis gossypii Glover, Nezara viridula (L.) and Thrips tabaci Lind. in field. Online J. Biol. Sci. 1:941-945.

Baker, E.A. 1982. Chemistry and morphology of plant epicuticular waxes, p. 139-165. In: Cutler, D.F., K.L. Alvin, and C.E. Price (eds.). The plant cuticle. Academic Press, London, UK.

Balint, J., N. Burghardt, M. Hohn, B. Penzes, and J. Fail. 2013. Does epidermal thickness influence white cabbage resistance against onion thrips (Thrips tabaci)? Notulae Botanicae Horti Agrobotanici ClujNapoca 41:444-449.

Bergman, D.K., J.W. Dillwith, A.A. Zarrabi, J.L. Caddel, and R.C. Berberet. 1991. Epicuticular lipids of alfalfa relative to its susceptibility to spotted alfalfa aphids (Homoptera: Aphididae). Environ. Entomol. 20:781-785.

Blaney, W.M. and R.F. Chapman. 1970. The functions of the maxillary palps of Acrididae (Orthoptera). Entomol. Exp. Appl. 13:363-376.

Coudriet, D.L., A. Kishaba, J.D. McCreight, and G. Bohn. 1979. Varietal resistance in onions to thrips (Thrips tabaci). J. Econ. Entomol. 72:614-615.

Diaz-Montano, J., M. Fuchs, B.A. Nault, and A.M. Shelton. 2010. Evaluation of onion cultivars for resistance to onion thrips (Thysanoptera: Thripidae) and iris yellow spot virus. J. Econ. Entomol. 103:925-937.

Eigenbrode, S.D. 2004. The effects of plant epicuticular waxy blooms on attachment and effectiveness of predatory insects. Arthropod Struct. Dev. 33:91-102.

Eigenbrode, S.D. and K.E. Espelie. 1995. Effects of plant epicuticular lipids on insect herbivores. Annu. Rev. Entomol. 40:171-194.

Elmore, J.C. 1949. Thrips injury to onions grown for seed. J. Econ. Entomol. 42:756-760.

Gent, D.H., H.F. Schwartz, and R. Khosla. 2004. Distribution and incidence of iris yellow spot virus in Colorado and its relation to onion plant population and yield. Plant Dis. 88:446-452.

Gülz, P.G., E. Müller, and T. Herrmann. 1993. Epicuticular leaf waxes of the hop (Humulus lupulus). Chemical composition and surface structures. Zeitschrift fur Naturforschung 48c:689696.

Gülz, P.G., E. Müller, and K. Schmitz. 1992. Chemical composition and surface structures of epicuticular leaf waxes of Ginko biloba, Magnolia grandiflora, and Liriodendron tulipifera. Zeitschrift fur Naturforschung 47c:516-526.
Harris, D.C. 2003. Standard addition, p. 101-107. In: Byrd, M.L. (ed.). Quantitative chemical analysis. 6th Ed. W.H. Freeman, New York, NY.

Herron, G.A., T.M. James, J. Rophail, and J. Mo. 2008. Australian populations of onion thrips, Thrips tabaci Lindeman (Thysanoptera: Thripidae), are resistant to some insecticides used for their control. Austral. J. Entomol. 47:361-364.

Jeffree, C.E. 1986. The cuticle, epicuticular waxes and trichomes of plants, with reference to their structure, functions and evolution, $p$. 23-64. In: Juniper, B.E. and T.R.E. Southwood (eds.). Insects and the plant surface. Edward Arnold, London, UK.

Jones, H.A., S.F. Bailey, and S.L. Emsweller. 1934. Thrips resistance in onion. Hilgardia 8:215-232.

Jones, H.A., S.F. Bailey, and S.L. Emsweller. 1935. Field studies of Thrips tabaci Lind. with especial reference to resistance in onions. J. Econ. Entomol. 28:678-680.

Jones, H.A., A.E. Clarke, and F.J. Stevenson. 1944. Studies in the genetics of the onion (Allium cepa L.). Proc. Amer. Soc. Hort. Sci. 44:479-484.

Kogan, M. and E.F. Ortman. 1978. Antixenosis - A new term proposed to define Painter's 'nonpreference' modality of resistance. Entomol. Soc. Amer. Bul. 24:175-176.

Kolattukudy, P.E. and K.E. Espelie. 1985. Biosynthesis of cutin, suberin, and associated waxes, p. 161-207. In: Higuchi, T. (ed.). Biosynthesis and biodegradation of wood components. Academic Press, New York, NY.

Laudate, T. 2003. Imaging guidelines for scanning electron microscopy. Adv. Materials Processes July:23-25.

Lowe, H.J.B., G.J.P. Murphy, and M.L. Parker. 1985. Non-glaucousness, a probable aphid-resistance character of wheat. Ann. Appl. Biol. 106:555-560.

Maughan, F.B. and G.F. MacLeod. 1936. Further studies of onion varieties and onion thrips. J. Econ. Entomol. 29:335-339.

Mohan, S.K. and N. Molenaar. 2005. Powdery mildew caused by Leveillula taurica on glossy leaf genotypes of onion in Idaho. Plant Dis. 89:431.

Molenaar, N. 1984. Thrips (Thrips tabaci L.) resistance and epicuticular wax characteristics of nonglossy and glossy onions (Allium cepa L.). PhD diss., Univ. of Wisconsin, Madison, WI.

Mote, U.N. and H.N. Sonone. 1977. Relative susceptibility of different varieties of onion (Allium cepa) to thrips (Thrips tabaci Lind.). J. Maharashtra Agr. Univ. 2:152-155.

Muchero, W., J.D. Ehlers, and P.A. Roberts. 2010. QTL analysis for resistance to foliar damage caused by Thrips tabaci and Frankliniella schultzei (Thysanoptera: Thripidae) feeding in cowpea [Vigna unguiculata (L.) Walp.]. Mol. Breed. 25:47-56.

Nault, B.A., A.M. Shelton, C.L. Hsu, and C.A. Hoepting. 2012. How to win the battle against onion thrips. 20 May 2014. $<$ http:// www.hort.cornell.edu/expo/proceedings/2012/Onions/onion Nault.pdf $>$. Painter, R.H. 1951. Insect resistance in crop plants. MacMillan, New York, NY.

Pawar, B.B., A.V. Patil, and H.N. Sonone. 1975. A thrips resistant glossy selection in white onions. Res. J. Mahatma Phule Agr. Univ. 6:152-153.

Rhee, Y., A. Hlousek-Radojcic, J. Ponsamuel, D. Liu, and D. PostBeittenmiller. 1998. Epicuticular wax accumulation and fatty acid elongation activities are induced during leaf development of leeks. Plant Physiol. 116:901-911.

Shelton, A.M., J.Z. Zhao, B.A. Nault, J. Plate, F.R. Musser, and E. Larentzaki. 2006. Patterns of insecticide resistance in onion thrips (Thysanoptera: Thripidae) in onion fields in New York. J. Econ. Entomol. 99:1798-1804.

Shock, C., E. Feibert, L. Jensen, S. Krishna Mohan, and L. Saunders. 2008. Onion variety response to iris yellow spot virus. HortTechnology 18:1063-1068.

Städler, E. 1986. Oviposition and feeding stimuli in leaf surface waxes, p. 105-121. In: Juniper, B.E. and T.R.E. Southwood (eds.). Insects and the plant surface. Edward Arnold, London, UK. 
Starks, K.J. and D.E. Weibel. 1981. Resistance in bloomless and sparse-bloom sorghum to greenbugs. Environ. Entomol. 10:963965.

Stork, N.E. 1980. Role of waxblooms in preventing attachment to Brassicas by the mustard beetle, Phaedon cochleariae. Entomol. Exp. Appl. 28:100-107.

Thibout, E., J. Auger, and C. Lecomte. 1982. Host plant chemicals responsible for attraction and oviposition in Acrolepiopsis assectella. Proc. 5th Intl. Symp. Insect-Plant Relationships. p. 107115.
Tulloch, A.P. 1976. Chemistry of waxes of higher plants, p. 236-287. In: Kolattukudy, P.E. (ed.). Chemistry and biochemistry of natural waxes. Elsevier, Amsterdam, The Netherlands.

Walton, T.J. 1990. Waxes, cutin and suberin, p. 105-158. In: Dey, P.M. and J.B. Harborne (eds.). Methods in plant biochemistry. Academic Press, London, UK.

Woodhead, S. and R.F. Chapman. 1986. Insect behavior and the chemistry of plant surface waxes, p. 123-135. In: Juniper, B.E. and T.R.E. Southwood (eds.). Insects and the plant surface. Edward Arnold, London, UK. 